\title{
Activation of the Nrf2/HO-1 Pathway by Amomum villosum Extract Suppresses LPS-Induced Oxidative Stress In Vitro and Ex Vivo
}

\author{
Dong-Woo Lim (D), ${ }^{1}$ Hee-Jin Choi, ${ }^{2}$ Sun-Dong Park $\left(\mathbb{D},{ }^{3}\right.$ Hyuck Kim ${ }^{(D)},{ }^{4,5}$ Ga-Ram Yu, ${ }^{5}$ \\ Jai-Eun Kim $\mathbb{D}^{1}{ }^{1}$ and Won-Hwan Park $\mathbb{D}^{5}$ \\ ${ }^{1}$ Department of Pathology, College of Korean Medicine, Dongguk University, Goyang-si 10326, Republic of Korea \\ ${ }^{2}$ Department of Korean Medical Science, College of Korean Medicine, Pusan National University, Yangsan-si 50612, \\ Republic of Korea \\ ${ }^{3}$ Department of Prescription, College of Korean Medicine, Dongguk University, Goyang-si 10326, Republic of Korea \\ ${ }^{4}$ Institute of Korean Medicine, Dongguk University, 32 Dongguk-ro, Goyang-si 10326, Republic of Korea \\ ${ }^{5}$ Department of Diagnostics, College of Korean Medicine, Dongguk University, Dongguk-ro 32, Goyang-si 10326, Republic \\ of Korea
}

Correspondence should be addressed to Won-Hwan Park; diapwh@dongguk.ac.kr

Received 30 September 2019; Revised 30 March 2020; Accepted 16 April 2020; Published 4 May 2020

Academic Editor: Srinivas Nammi

Copyright (c) 2020 Dong-Woo Lim et al. This is an open access article distributed under the Creative Commons Attribution License, which permits unrestricted use, distribution, and reproduction in any medium, provided the original work is properly cited.

\begin{abstract}
Despite its deleterious effects on living cells, oxidative stress plays essential roles in normal physiological processes and provides signaling molecules for cell growth, differentiation, and inflammation. Macrophages are equipped with antioxidant mechanisms to cope with intracellular ROS produced during immune response, and Nrf2 (NF-E2-related factor 2)/HO-1 (heme oxygenase-1) pathway is an attractive target due to its protective effect against ROS-induced cell damage in inflamed macrophages. We investigated the effects of ethanol extract of $A$. villosum (AVEE) on lipopolysaccharide- (LPS-) stimulated inflammatory responses generated via the Nrf2/HO-1 signaling pathway in murine peritoneal macrophages and RAW 264.7 cells. AVEE was found to suppress the NF- $\kappa \mathrm{B}$ signaling pathway, thus, to reduce proinflammatory cytokine, nitric oxide, and prostaglandin levels in peritoneal macrophages and Raw 264.7 cells treated with LPS, and to enhance HO-1 expression by activating Nrf2 signaling. Furthermore, these anti-inflammatory effects of AVEE were diminished when cells were pretreated with SnPP (a HO-1 inhibitor). HPLC analysis revealed AVEE contained quercetin, a possible activator of the Nrf2/ HO-1 pathway. These results show A. villosum ethanol extract exerts anti-inflammatory effects by activating the Nrf2/HO-1 pathway in LPS-stimulated macrophages.
\end{abstract}

\section{Introduction}

Oxidative stress can be defined as an imbalance surfeit of ROS (reactive oxygen species) production as compared with ROS depletion by antioxidant defense systems [1]. Despite their deleterious effects, ROS play crucial roles in the physiological processes and metabolisms of organisms that utilize oxygen $[2,3]$. At the physiological level, ROS act as key signaling molecules for cell growth, differentiation, and inflammation [4]. However, when ROS levels are excessive, they cause oxidative damage to biomolecules such as lipids, proteins, and DNA [5] and can induce metabolic dysfunctions and apoptosis [6].

Inflammation is complex physiological response to noxious stimuli, such as physical or chemical injuries, or infections [7]. Excessive ROS induced by, for example, lead, carbon tetrachloride $\left(\mathrm{CCl}_{4}\right)$, or LPS can activate MAPK and $\mathrm{NF}-\kappa \mathrm{B}$ pathways and initiate inflammatory responses [8-11]. Of these ROS inducing agents, LPS has been intensively studied in the context of inflammatory response progression in macrophages [12]. 
Resident macrophages are activated after stimulation of toll-like receptors (TLRs), which act as primary LPS receptors, and, when activated, TLRs signal proinflammatory cytokine production, and hence, initiating inflammation [13]. ROS production also occurs during phagocytosis [14] and macrophage differentiation [15] and increases in intracellular ROS caused by respiratory burst during phagocytosis can be lethal to macrophages and cause apoptosis [16]. However, macrophages are equipped with antioxidant enzymes to counter endogenous ROS production. Accordingly, inflammation, oxidative stress, and the expressional statuses of antioxidant enzymes are closely interrelated [17].

Nrf2 (NF-E2-related-factor-2) is a representative, redoxsensitive transcription factor that controls the expressions of antioxidant enzymes such as $\mathrm{NADPH}$, quinone oxidoreductase (NQO1), glutamate cysteine ligase (GCL), glutathione S-transferase (GST), catalase (CAT), and heme oxygenase-1 (HO-1) [18-20] and its functions and those of its downstream genes have been intensively studied in the context of oxidative stress and chemically induced cellular damage [21].

$\mathrm{HO}-1$ is induced by oxidative and inflammatory signals in most cells [22]. HO-1 catalyzes the degradation of heme to produce carbon monoxide, free iron, and biliverdin [23], the latter of which is converted into bilirubin, which is largely responsible for the protective effects of HO-1 [24]. The regulation of $\mathrm{HO}-1$ expression is now regarded a therapeutic target for several diseases [25], and in one study conducted using HO-1 deficient mouse models, it was found that HO-1 fundamentally modulates early inflammatory response [26]. Therefore, concerted efforts are being made to discover natural product-derived modulators of the Nrf2/HO- 1 pathway to conquer chronic inflammatory diseases [27].

Amomum villosum Lour. (A. villosum) belongs to the Zingiberaceae family and is used to treat gastrointestinal disorders and nausea in traditional Chinese medicine $[28,29]$. Previous studies have shown A. villosum has analgesic, anti-inflammatory [30], and antimicrobial [31] properties and ameliorates anti-nonalcoholic fatty liver disease (NAFLD) [28]. Furthermore, the high volatile oil and polysaccharide contents of A. villosum suggest it probably has other undiscovered pharmacologic effects. However, its effects on murine macrophages have not been investigated. In the present study, we investigated the effects of an ethanol extract of A. villosum (AVEE) on LPS-stimulated murine peritoneal macrophages and Raw 264.7 cells and mechanisms responsible for these effects.

\section{Materials and Methods}

2.1. Reagents and Animals. Dulbecco's Modified Eagle Medium (DMEM), fetal bovine serum (FBS), and penicillin/ streptomycin solution were purchased from Invitrogen (Carlsbad, CA, USA). Primary antibodies for iNOS, COX-2, HO-1, Nrf2, p65, I $\kappa$ B- $\alpha$, p-I $\kappa$ B- $\alpha, \beta$-actin, and lamin B were purchased from Santa Cruz (Santa Cruz, CA, USA). ELISA kits for IL1 $\beta$, TNF- $\alpha$, and $\mathrm{PGE}_{2}$ were purchased from R\&D Systems (Minneapolis, MN, USA). Escherichia coli lipopolysaccharide (LPS), dimethyl sulfoxide (DMSO), and Griess reagents were purchased from Sigma Aldrich Corp. (St Louis, MO, USA). Tin protoporphyrin IX dichloride (SnPP IX, a HO-1 inhibitor) and cobalt protoporphyrin (CoPP, a HO-1 inducer) were obtained from Porphyrin Products (Logan, UT, USA). Radioimmunoprecipitation assay (RIPA) buffer and a NE-PER nuclear extraction kit were purchased from Thermo Scientifics (Waltham, MA, USA). A TransAM kit, which was used to measure the DNAbinding activity of NF- $\kappa \mathrm{B}$, was obtained from Active Motif (Carlsbad, CA, USA). A Bio-Rad Protein Assay kit (based on the Bradford method) used for determining protein concentrations was purchased from Bio-Rad Laboratories (Hercules, CA, USA).

Peritoneal macrophages were isolated from 10-week old C57/BL6J mice using 4\% thioglycollate medium. Briefly, thioglycollate $(1 \mathrm{~mL})$ was injected intraperitoneally $96 \mathrm{~h}$ before sacrifice. Mice were anesthetized with mixture of Zoletil and Rompun, injected intraperitoneally with $10 \mathrm{~mL}$ of RPMI, and later, $6-8 \mathrm{~mL}$ of peritoneal fluid was withdrawn using a syringe. The fluid was then centrifuged to separate cells from debris. The cells obtained were incubated for $3 \mathrm{~h}$ at $37^{\circ} \mathrm{C}$ and washed with Dulbecco's PhosphateBuffered Saline (DPBS), and adherent macrophages were collected for further study. All protocols for animal experiments were approved beforehand by the ethics committee of Dongguk University (IACUC-2016-055).

2.2. Preparation of AVEE. The fruits of Amomum villosum (Zingiberaceae) were purchased from the Dongguk University Hospital Herbal Drugstore (Ilsan, Republic of Korea); a voucher specimen was deposited at the College of Korean Medicine at Dongguk University. Fruits (50 g) were extracted two times with $70 \%$ ethanol $(1 \mathrm{~L})$ for $2 \mathrm{~h}$ at $95^{\circ} \mathrm{C}$, and the extract obtained was passed through Whatman \#2 filter paper. Evaporation of the filtrate in vacuo resulted in a $70 \%$ ethanol extract $(6.8 \mathrm{~g}, 13.6 \mathrm{w} / \mathrm{w} \%)$, which was then suspended in distilled water $(100 \mathrm{~mL})$, filtered, and dried in vacuo. The residue obtained was dissolved in hot ethanol, filtered, and reevaporated to obtain AVEE (660 mg, $1.32 \mathrm{w} / \mathrm{w}$ $\%$ ). For experiments, AVEE was dissolved in DMSO (dimethyl sulfoxide) at a concentration of $0.05 \%$. Supportive studies showed that, at the concentrations used, DMSO had no effect on cell viabilities.

2.3. Cell Viability Assay. Mouse peritoneal macrophages and RAW 264.7 cells (a macrophage cell-line; American Type Culture Collection) were maintained in FBS-supplemented (10\%, v/v) DMEM, $100 \mathrm{U} / \mathrm{mL}$ penicillin, and $100 \mu \mathrm{g} / \mathrm{mL}$ streptomycin. Cells were incubated in a $5 \% \mathrm{CO}_{2}$ humidified atmosphere at $37^{\circ} \mathrm{C}$. Cell viabilities were measured using an MTT assay. Briefly, mouse peritoneal macrophages and RAW 264.7 cells were plated at a concentration of $2 \times 10^{5}$ cells per well in 24-well plates and treated with different concentrations of AVEE for $24 \mathrm{~h}$. Supernatants were discarded and $0.5 \mathrm{mg} / \mathrm{mL}$ of MTT reagent was added. After $4 \mathrm{~h}$ of incubation at $37^{\circ} \mathrm{C}$ under $5 \% \mathrm{CO}_{2}$, supernatants were removed and DMSO was added to dissolve the formazan 
crystals formed in live cells. Optical densities were measured at $540 \mathrm{~nm}$ using an ELISA plate reader.

\subsection{Determination of the Expression of Inflammatory Cyto-} kine Genes in Peritoneal Macrophages. Isolated murine macrophages were seeded in a 6 -well plate, at $5 \times 10^{5}$ cells per well, preincubated with AVEE for $30 \mathrm{~min}$, and treated with LPS $(1 \mu \mathrm{g} / \mathrm{mL})$ for $24 \mathrm{~h}$. Intact mRNA was manually isolated using Trizol reagent (Thermo Fisher, Waltham, USA) according to the manufacturer's instructions and used to synthesize cDNA. Quantitative real-time PCR was conducted using SYBR green fluorescence dye over 45 amplification cycles consisting of denaturation at $95^{\circ} \mathrm{C}$ for $10 \mathrm{~s}$, annealing at $55^{\circ} \mathrm{C}-58^{\circ} \mathrm{C}$ for $15 \mathrm{~s}$, and extension at $72^{\circ} \mathrm{C}$ for $15 \mathrm{~s}$. The following primers were used: IL- $1 \beta$-forward, $5^{\prime}-$ GCCCATCCTCTGTGACTCAT-3', reverse, $5^{\prime}$-AGGCCACAGCTATTTTGTCG-3'; IL-6-forward, 5'-AGTTGCCTTCTTGGGACTGA-3', reverse, $5^{\prime}$-CAGAATTGCCATTGCACAAC- $3^{\prime}$; TNF- $\alpha$-forward, $5^{\prime}$-GAACTGGCAGAAGAGGCAG-3', reverse, 5'-AGGGTCTGGGCCATAGAACT-3'; COX-2-forward, 5'-AGAAGGAAATGGCTGCAGAA-3', reverse, $5^{\prime}$-GCTCGGCTTCCAGTATTGAG$3^{\prime}$; and beta-actin ( $\beta$-actin) - forward, $5^{\prime}$-GCAAGTGCTTCTAGGCGGAC-3', reverse; $5^{\prime}$-AAGAAAGGGTGTAAAACGCAGC- $3^{\prime}$ used as the internal control. Ct results with a melting curve were checked using Roche LightCycler 480 software (Roche Applied Science, USA). Ct values for the expression of each cytokine gene were normalized using $\mathrm{Ct}$ values of $\beta$-actin gene expression.

2.5. Measurement of Nitric Oxide Production. NO production was measured using Griess reagent. Briefly, RAW 264.7 cells were seeded at $2 \times 10^{5}$ cells per well in 24-well plates and treated with AVEE with or without SnPP IX plus LPS for $18 \mathrm{~h}$. Next, $100 \mu \mathrm{L}$ aliquots of media were mixed with $100 \mu \mathrm{L}$ Griess reagent $(0.1 \% N$-(1-naphthyl)ethylenediamine and $1 \%$ sulfanilamide in $5 \%$ phosphoric acid), and $15 \mathrm{~min}$ later absorbances were measured at $540 \mathrm{~nm}$ using a microplate reader (VersaMax, Molecular Devices, CA, USA).

\subsection{Measurement of PGE2, TNF- $\alpha$, and IL-1 $\beta$ Levels in Culture} Media. Levels of $\mathrm{PGE}_{2}$, TNF- $\alpha$, and IL- $1 \beta$ in culture media were measured using an ELISA kit. Briefly, RAW 264.7 cells were seeded at $2 \times 10^{5}$ per well in 24 -well plates and treated with AVEE with or without SnPP IX plus LPS for $18 \mathrm{~h}$. Culture media were then collected and the concentrations of PGE2, TNF- $\alpha$, and IL- $1 \beta$ were measured using an ELISA kit.

2.7. Preparation of Nuclear and Cytosolic Fractions. RAW 264.7 cells were seeded at $2 \times 10^{6}$ cells per dish in $60 \mathrm{~mm}$ culture dishes and treated with various concentrations of AVEE and LPS for $1 \mathrm{~h}$. Nuclear and cytosolic proteins were isolated using an NE-PER nuclear extraction kit.

2.8. Western Blot Analysis. Whole proteins were isolated using RIPA buffer and quantified using the Bradford method. Equal amounts of proteins were separated by SDSPAGE (10\%) and transferred to nitrocellulose membrane, which were then blocked with $5 \%$ skim milk, incubated with primary antibodies at $4^{\circ} \mathrm{C}$ overnight, washed three times, and incubated with secondary antibodies at $4^{\circ} \mathrm{C}$ for $1 \mathrm{~h}$. Protein was detected using a Fusion Solo chemiluminescence system (Vilber Lourmat, Marne-la-Vallée, France) and analyzed using Bio-1D advanced software.

2.9. DNA-Binding Activity of NF- $\kappa B$. RAW 264.7 cells were seeded at $2 \times 10^{6}$ cells per dish in $60 \mathrm{~mm}$ culture dishes and treated with various concentrations of AVEE and LPS for $1 \mathrm{~h}$. DNA-binding activity of NF- $\kappa \mathrm{B}$ was measured using a TransAM kit according to manufacturer's instructions. Briefly, $20 \mu \mathrm{g}$ of nuclear proteins was diluted in complete lysis buffer (1 M DTT, protease inhibitor cocktail, lysis buffer AM2) and added to wells with $30 \mu \mathrm{L}$ of complete binding buffer (1 M DTT, herring sperm DNA, binding buffer AM3). Plates were incubated for $1 \mathrm{~h}$ with agitation $(100 \mathrm{rpm})$ and washed three times, and then $100 \mu \mathrm{L}$ of NF$\kappa \mathrm{B}$ antibody (1:1000 dilution) was added and samples were incubated for an additional $1 \mathrm{~h}$ with mild agitation. After washing each well three times, $100 \mu \mathrm{L}$ of HRP-conjugated antibody (1:1000 dilution) was added, and plates were incubated for $1 \mathrm{~h}$ with agitation. Wells were then washed four times, $100 \mu \mathrm{L}$ of developing solution was added to each well, kept for 5 min in the dark. Finally, stop solution was added $(100 \mu \mathrm{L} /$ well $)$ and absorbance was read on a spectrophotometer at $450 \mathrm{~nm}$.

2.10. Immunofluorescence Assay. RAW 264.7 cells were seeded onto Lab-Tek II chamber slides and incubated for $24 \mathrm{~h}$. Various concentrations of AVEE were then added with LPS and incubated for $1 \mathrm{~h}$. Cells were then fixed in formalin, blocked with $1 \%$ bovine serum albumin in PBS for $30 \mathrm{~min}$, treated with primary antibody diluted $1: 200$ in PBS overnight at $4{ }^{\circ} \mathrm{C}$, and incubated with fluorescein isothiocyanate(FITC-) labeled secondary antibody diluted 1:2000 in PBS for $1 \mathrm{~h}$. To detect nuclei, cells were treated with $1 \mu \mathrm{g} / \mathrm{mL}$ of DAPI for $5 \mathrm{~min}$, washed three times with PBS, and mounted on chamber slides using Dako Fluorescent mounting medium. Stained cells were observed and photographed using a fluorescence microscope (BX50, Olympus, Tokyo, Japan).

2.11. High Performance Liquid Chromatography (HPLC) of $A V E E$. The HPLC unit used was SNKNM series instrument equipped with a sample injector and a diode-array UV/VIS detector (DAD) (SYKAM, Germany). An Inertsil ODS analytical C- 18 column $(4.6 \times 150 \mathrm{~nm} ; 5 \mu \mathrm{m}$, GL Science Inc., Tokyo, Japan) was used, with an injection volume of $20 \mu \mathrm{L}$. The mobile phase comprised water (A) and methanol (B), with an applied linear gradient of $10 \%$ increasing to $100 \% \mathrm{~B}$ within $40 \mathrm{~min}$. The column was prewashed with $10 \% \mathrm{~B}$ for $20 \mathrm{~min}$, after which the condition maintained $20 \mathrm{~min}$ for equilibration. The flow rate was adjusted to $0.7 \mathrm{~mL} / \mathrm{min}$, and the detection was adjusted to $254 \mathrm{~nm}$ wavelength. 
2.12. Data Analysis. Results are presented as the mean$\mathrm{s} \pm$ standard deviation of at least three independent experiments performed in triplicate. Data was analyzed using One-Way ANOVA with Dunnett's multiple comparison tests. $P$ values of $<0.05,<0.01$, or $<0.005$ were considered significant, as indicated.

\section{Results}

3.1. Effect of AVEE on RAW 264.7 Cell Viability. To determine the optimal AVEE concentration, its effects on RAW 264.7 cell viability were assessed using the MTT assay (Figure 1(a)). Cells were incubated with various concentrations of AVEE (12.5, 25, 50, 100, and $150 \mu \mathrm{g} / \mathrm{mL}$ ) for $24 \mathrm{~h}$. No significant difference in cell viability was observed up to a concentration of $100 \mu \mathrm{g} / \mathrm{mL}$ (94.0\% of the control), and thus AVEE concentrations of $12.5,25,50$, or $100 \mu \mathrm{g} / \mathrm{mL}$ were used in subsequent experiments.

3.2. A VEE Inhibited $i N O S$ and COX-2 Expressions in Inflamed $R A W 264.7$ Cells. The influence of AVEE on the protein expressions of iNOS and COX-2 was investigated in LPSstimulated macrophages. RAW 264.7 cells were preincubated with AVEE before being treated with LPS. As was expected, immunoblotting showed LPS markedly increased iNOS and COX-2 protein levels. AVEE significantly and dose-dependently inhibited the expression of iNOS (Figure 1(b)) and obviously suppressed COX-2 levels at $100 \mu \mathrm{g} / \mathrm{mL}$ (Figure 1(c)).

\subsection{AVEE Reduced the LPS-Induced Productions of NO, PGE,} and Inflammatory Cytokines in RAW 264.7 Cells. LPS-induced increases in $\mathrm{NO}$ and $\mathrm{PGE}_{2}$ (Figures 2(a) and 2(b)) levels were reduced by AVEE pretreatment. Furthermore, ELISA showed AVEE dose-dependently suppressed LPS induced increases in the levels of TNF- $\alpha$ and IL-1 $\beta$ (Figures 2(c) and 2(d)).

3.4. AVEE Inhibited NF- $\kappa B$ Signal Activation in RAW 264.7 Cells. We also examined the effects of AVEE on NF- $\kappa \mathrm{B}$ translocation and $\mathrm{I} \kappa \mathrm{B}-\alpha$ phosphorylation in RAW 264.7 cells using immunoblot, TransAM kit, and immunofluorescence images. AVEE dose-dependently inhibited the nuclear translocation of NF- $\kappa \mathrm{B}$ (Figure 3(a)) and suppressed LPSinduced cytoplasmic I $\kappa \mathrm{B}-\alpha$ degradation and phosphorylation. Moreover, AVEE also suppressed LPS-induced NF- $\kappa \mathrm{B}$ DNA-binding activity (Figure $3(\mathrm{~b})$ ). These results were confirmed by immunofluorescence microscopic images (Figure 3(c)).

3.5. AVEE Induced HO-1 Expression and the Nuclear Translocation of Nrf2 in RAW 264.7 Cells. The induction of HO-1 expression was monitored after treating RAW 264.7 cells with AVEE. The expression of HO-1 was apparent after $3 \mathrm{~h}$ of treatment and peaked at $12 \mathrm{~h}$ in the presence of $100 \mu \mathrm{g} /$ $\mathrm{mL}$ AVEE (Figure 4(a)). And we confirmed that AVEE increased HO-1 expression in combination with $10 \mu \mathrm{M}$ CoPP (a HO-1 inducer) (Figure 4(b)). Furthermore, immunoblotting showed obvious changes in the localization of Nrf2 from cytoplasm to nuclei after $3 \mathrm{~h}$ of AVEE treatment $(100 \mu \mathrm{g} / \mathrm{mL})$ (Figure $4(\mathrm{c}))$. The results indicate AVEE treatment promoted the nuclear translocation of $\mathrm{Nrf} 2$ and activated the Nrf2/HO-1 pathway to increase HO-1 level (Figure 4(d)).

3.6. AVEE Suppressed NO, PGE $E_{2}$, and Proinflammatory Cytokine Levels by Inducing HO-1 Expression. We investigated whether HO-1 inhibition influences the inhibitory effects of AVEE on LPS-stimulation, which was observed in result above. The inhibitory effects of AVEE pretreatment on the LPS-induced upregulations of NO, PGE2, TNF- $\alpha$, and IL- $1 \beta$ levels in RAW 264.7 were found to be significantly decreased by treating cells with $100 \mu \mathrm{M}$ of SnPP for $1 \mathrm{~h}$ before AVEE pretreatment (Figures 5(a)-5(d)).

\subsection{AVEE Inhibited Proinflammatory Gene Expression in} Mouse Peritoneal Macrophages. Isolated murine macrophages were incubated with or without AVEE for $24 \mathrm{~h}$ to determine the effect of AVEE treatment on cell viability. As was observed for RAW 264.7 cells, AVEE did not significantly affect viability at concentrations of $<100 \mu \mathrm{g} / \mathrm{mL}$, but at $200 \mu \mathrm{g} / \mathrm{mL}$, AVEE did significantly reduce cell viability (Figure 6(a)). Murine macrophages stimulated with $1 \mu \mathrm{g} / \mathrm{mL}$ LPS showed marked increases in the mRNA expressions of IL-6, IL- $1 \beta$, COX-2, and TNF- $\alpha$, but AVEE pretreatment $(100 \mu \mathrm{g} / \mathrm{mL})$ prevented these upregulations. When treatment naive macrophages were treated with AVEE, the expressions of these inflammatory genes increased slightly (Figures 6(b)$6(\mathrm{e}))$.

3.8. HPLC Analysis of AVEE. AVEE was analyzed by HPLC using a detection wavelength of $254 \mathrm{~nm}$. Three samples (AVEE, quercetin, and AVEE + quercetin) were run to enable accurate retention time comparisons. The results obtained showed AVEE contained quercetin, which is a known bioactive component of A. villosum (Figure 7) [32].

\section{Discussion}

The present study shows AVEE suppresses LPS-induced inflammatory response by suppressing oxidative stress via the Nrf2/HO-1 pathway. Macrophages of the murine peritoneal cavity have been widely used to investigate anti-inflammatory effects and mechanisms of natural products [33, 34]. LPS triggers macrophage activation through TLR4, and this activation results in the explosive production of proinflammatory cytokines [35]. In particular, excessive nitric oxide (NO) functions as proinflammatory mediator [36] and confers on macrophages the ability to kill invading pathogens [37]. In addition, the upregulation of inducible cyclooxygenase (COX-2) results in the inductions of various tissue-specific isomeric prostaglandins [38]. Furthermore, these proinflammatory 



(c)

FIGURE 1: Effects of AVEE on RAW 264.7 cell viability and on the LPS-induced expressions of proinflammatory enzymes. RAW 264.7 cells were incubated for $24 \mathrm{~h}$ in the presence of various concentrations of AVEE $(12.5,25,50,100$, or $150 \mu \mathrm{g} / \mathrm{mL})$. Cell viabilities were measured using an MTT assay (a). Cells were pretreated with various concentrations of AVEE $(12.5,25,50$, or $100 \mu \mathrm{g} / \mathrm{mL}) 3 \mathrm{~h} \mathrm{before} \mathrm{LPS} \mathrm{stimulation}$ and then incubated for a further $18 \mathrm{~h}$ in the presence of LPS $(1 \mu \mathrm{g} / \mathrm{mL})$. Protein levels of iNOS (b) and COX-2 (c) were detected by western blotting. Results are presented as the means \pm SDs of three independent experiments. ${ }^{\# \#} P<0.01$ versus treatment naïve controls. ${ }^{*} P<0.05$ and ${ }^{* *} P<0.01$ versus LPS treated controls.

markers are generally elevated in classically activated (M1) macrophages [39].

As was expected, LPS elicited inflammatory responses in macrophages and markedly increased $\mathrm{NO}$ and $\mathrm{PGE}_{2}$, TNF $\alpha$, IL- $1 \beta$, iNOS, and COX-2 levels, and all were significantly and dose-dependently reduced by pretreating cells with AVEE. NF- $\kappa B$ is a well-known p50/RelA (p65) heterodimeric transcription factor that is responsible for the expressions of various proinflammatory genes encoding cytokines and chemokines [40]. The DNA-binding activity of NF- $\kappa \mathrm{B}$ is modulated by $\mathrm{I} \kappa \mathrm{B}$ phosphorylation and degradation, which follow the activation of I $\kappa$ B kinase 


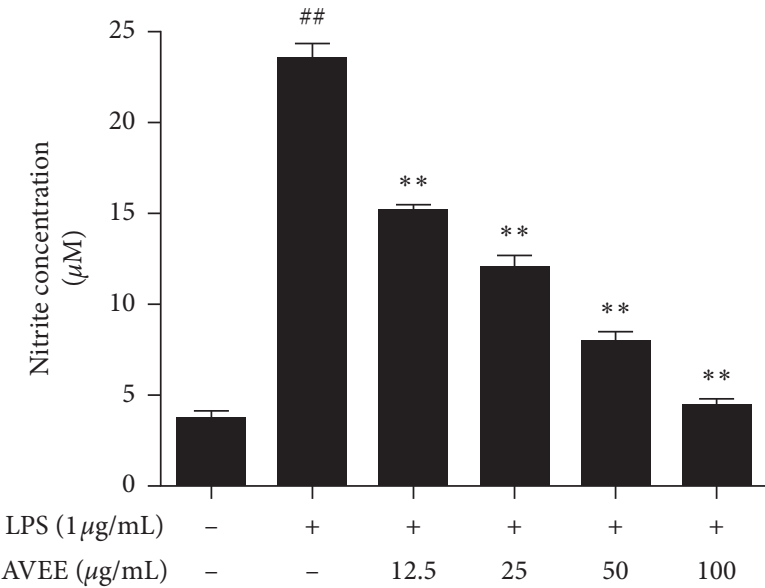

(a)

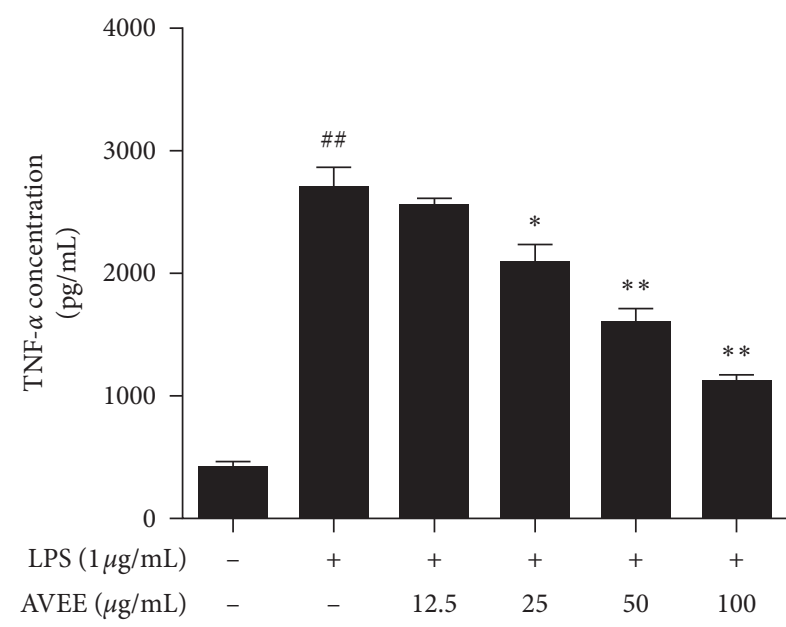

(c)

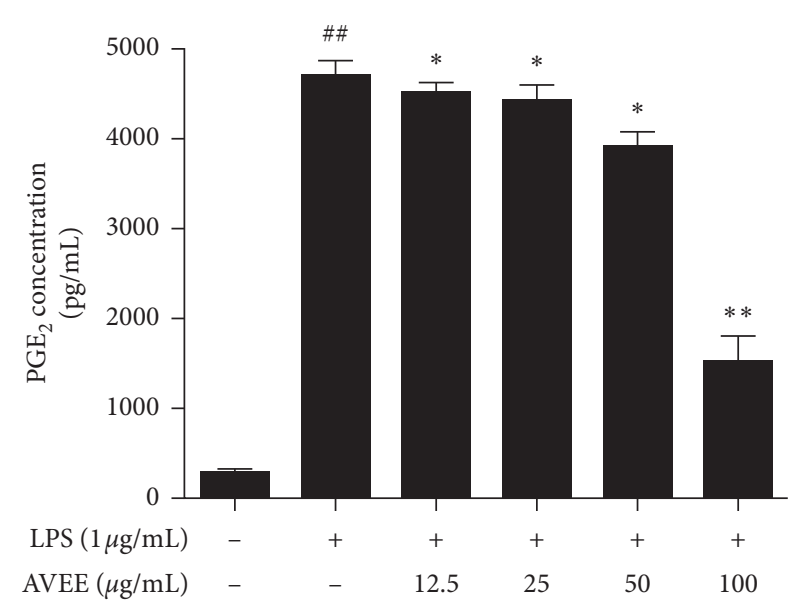

(b)

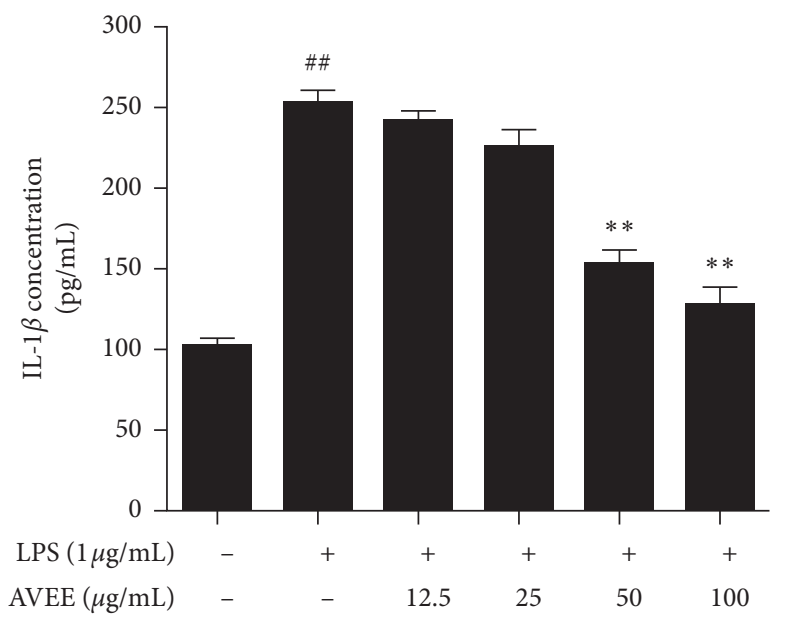

(d)

FIGURE 2: Effects of AVEE on the inductions of NO and inflammatory cytokines by LPS. RAW 264.7 cells were pretreated with the various concentrations of AVEE $(12.5,25,50$, or $100 \mu \mathrm{g} / \mathrm{mL}) 3 \mathrm{~h}$ before LPS stimulation, and then for a further $18 \mathrm{~h} \mathrm{in} \mathrm{the} \mathrm{presence} \mathrm{of} \mathrm{LPS}(1 \mu \mathrm{g} / \mathrm{mL})$. No concentrations were measured using a Griess reagent system (a). PGE 2 (b), TNF- $\alpha$ (c), and IL- $1 \beta$ (d) expressions were quantified by ELISA as described in Materials and Methods. Results are presented as the means \pm SDs of three independent experiments. ${ }^{\# \#} P<0.01$ versus treatment naïve controls. ${ }^{*} P<0.05$ and ${ }^{* *} P<0.01$ versus LPS controls.

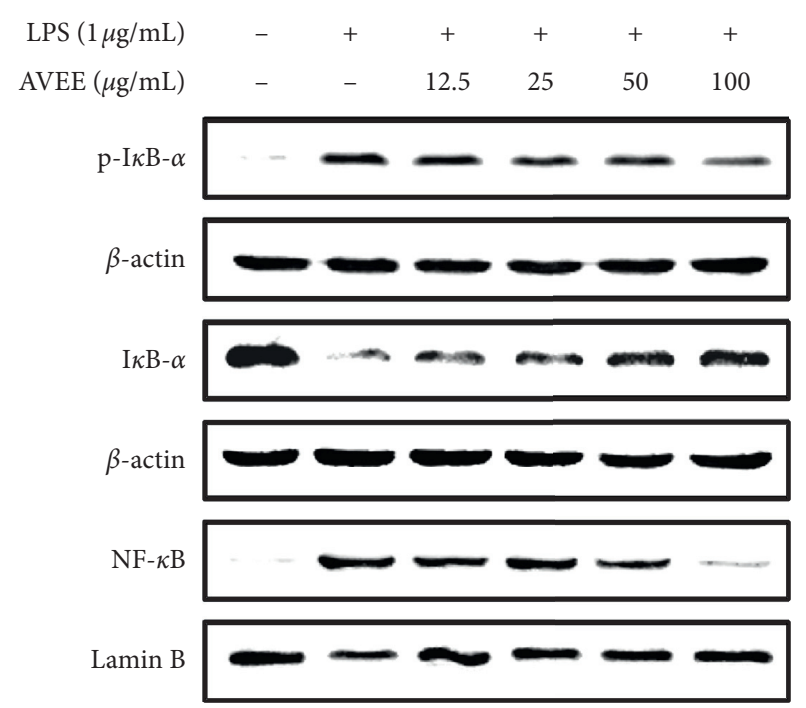

(a)

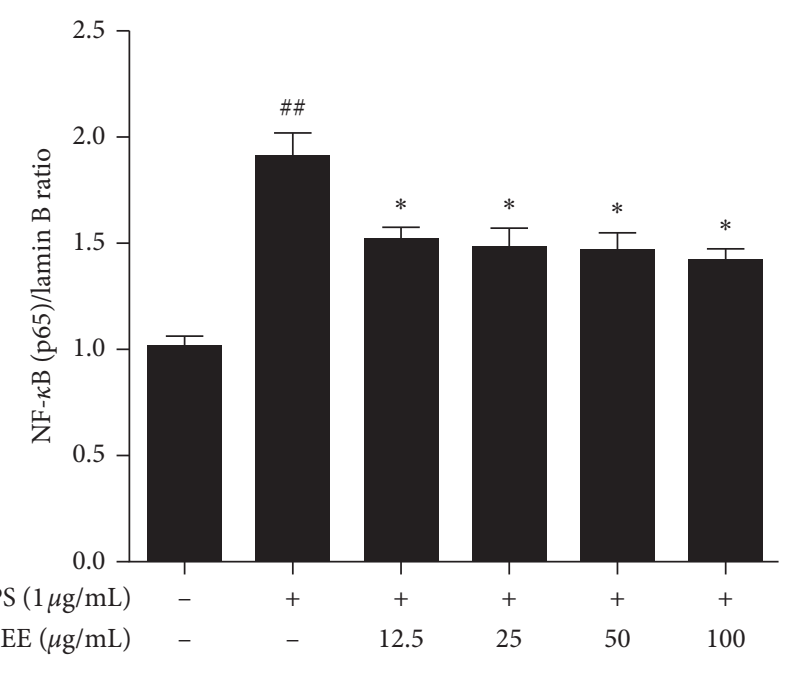

(b)

Figure 3: Continued. 

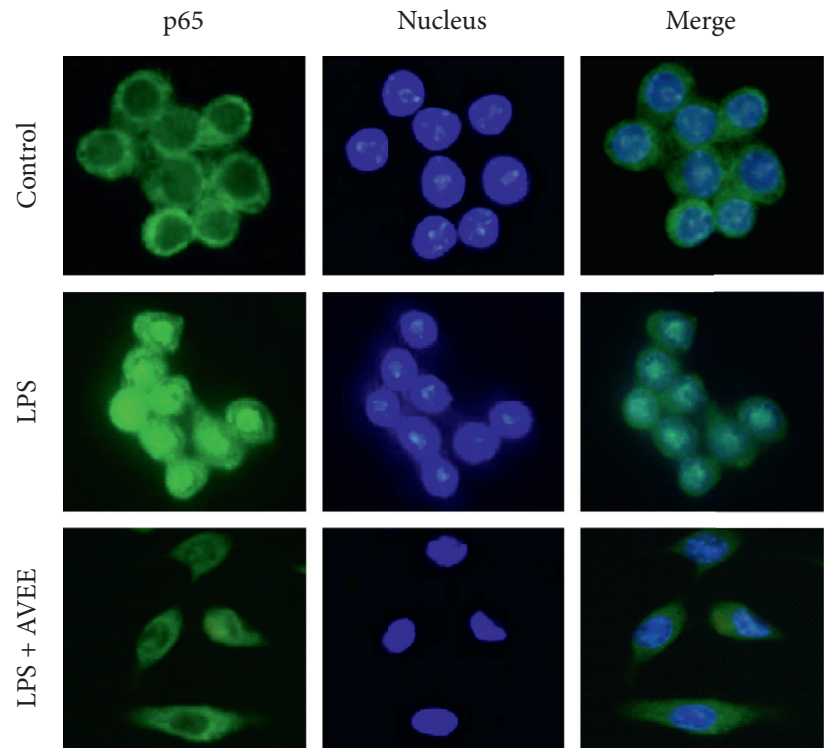

(c)

FIgURE 3: Effects of AVEE on LPS-induced NF- $\kappa$ B pathway activation. RAW 264.7 cells were treated with various concentrations of AVEE $(12.5,25,50$, or $100 \mu \mathrm{g} / \mathrm{mL})$ for $3 \mathrm{~h}$ and stimulated with LPS $(1 \mu \mathrm{g} / \mathrm{mL})$ for another $1 \mathrm{~h}$. Cytosolic I $\kappa$ B phosphorylation and NF- $\kappa \mathrm{B}$ translocation to nucleosomes were detected by Western blotting (a). NF- $\kappa$ B DNA-binding activity was assessed using a TransAM kit (b). Nuclear NF- $\kappa$ B translocation was visualized under an immunofluorescence microscope (c). Results are presented as the means \pm SDs of three independent experiments. ${ }^{\# \#} P<0.01$ versus treatment naïve controls. ${ }^{*} P<0.05$ versus LPS controls.
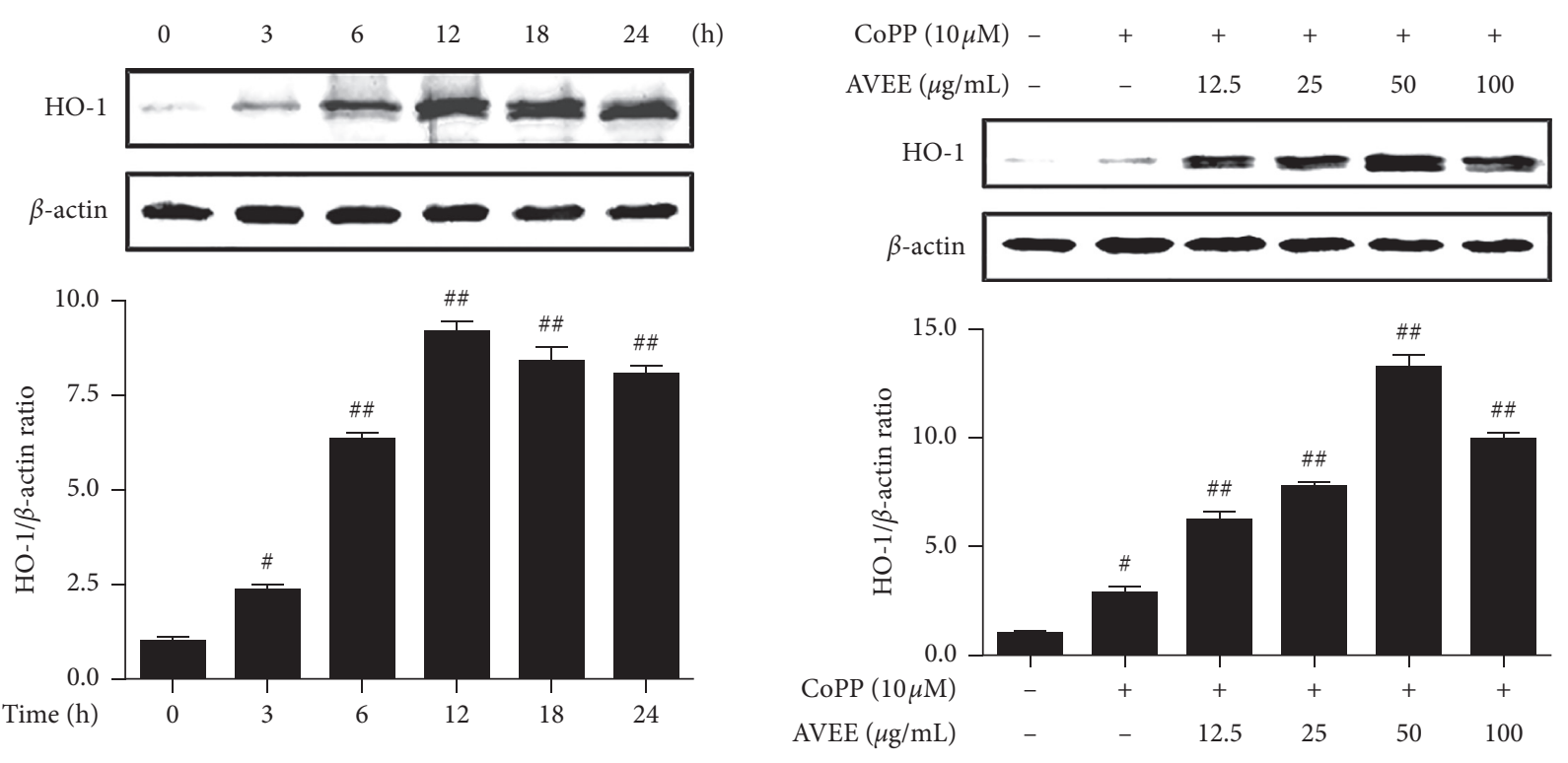

(a)

(b)

Figure 4: Continued. 

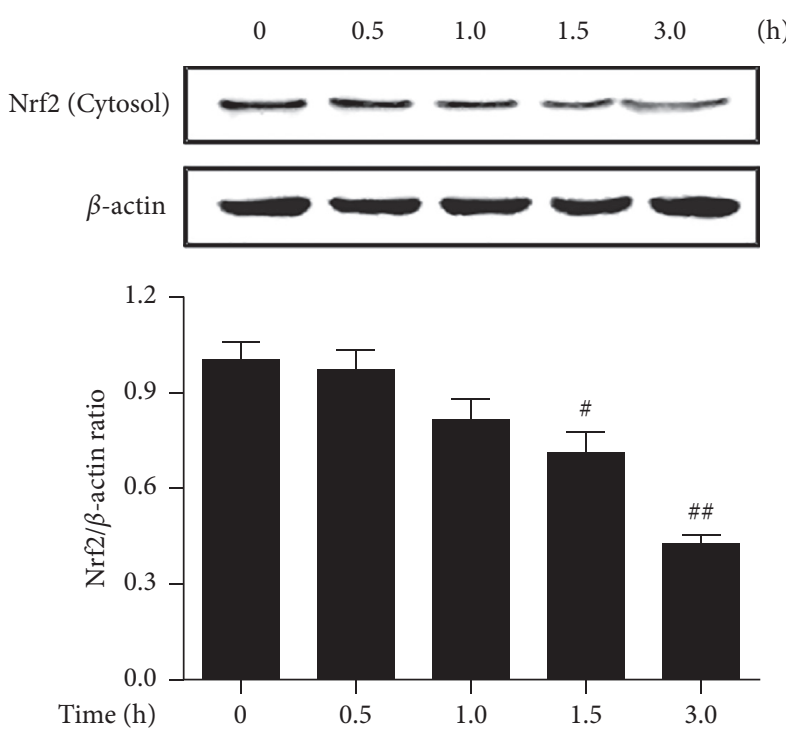

(c) (h)
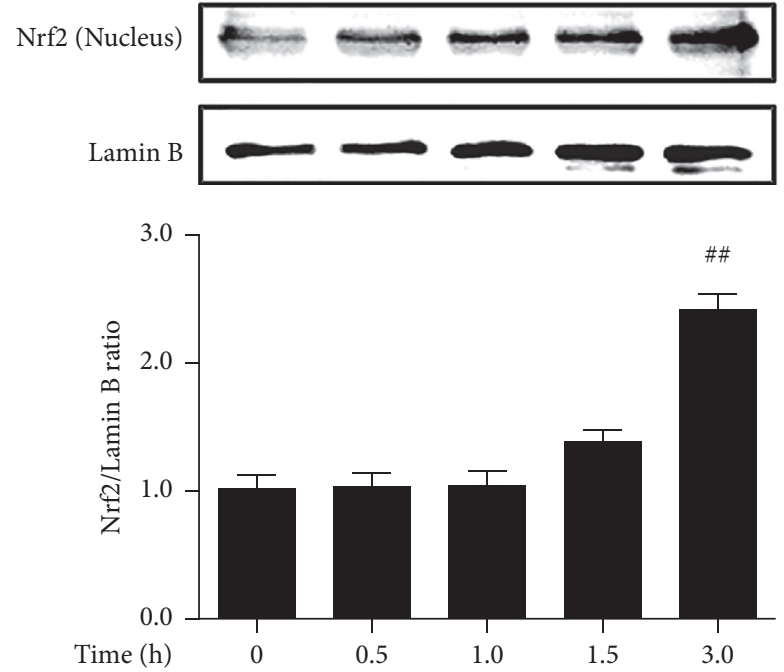

(d)

Figure 4: Effects of AVEE on HO-1 expression and the nuclear translocation of Nrf2. RAW264.7 cells were incubated with $100 \mu \mathrm{g} / \mathrm{mL}$ of AVEE for indicated times and HO-1 expression was examined by western blot analysis (a). RAW 264.7 cells were treated with various concentrations of AVEE $(12.5,25,50$, and $100 \mu \mathrm{g} / \mathrm{mL})$ for $18 \mathrm{~h} \mathrm{CoPP}(10 \mu \mathrm{M}$; a HO-1 inducer) was used as the positive control (b). Nrf2 expression levels of in cytoplasm (c) and nucleus (d) were assessed by Western blotting. Columns are the means \pm SDs of independent experiments. ${ }^{\#} P<0.05$ and ${ }^{\# \#} P<0.01$ versus treatment naïve controls.

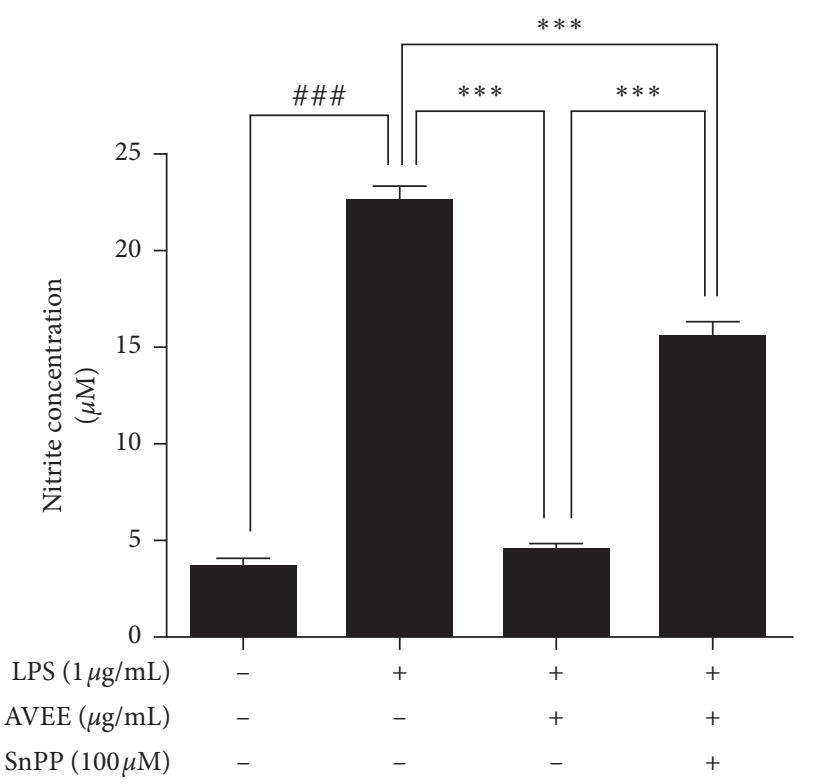

(a)

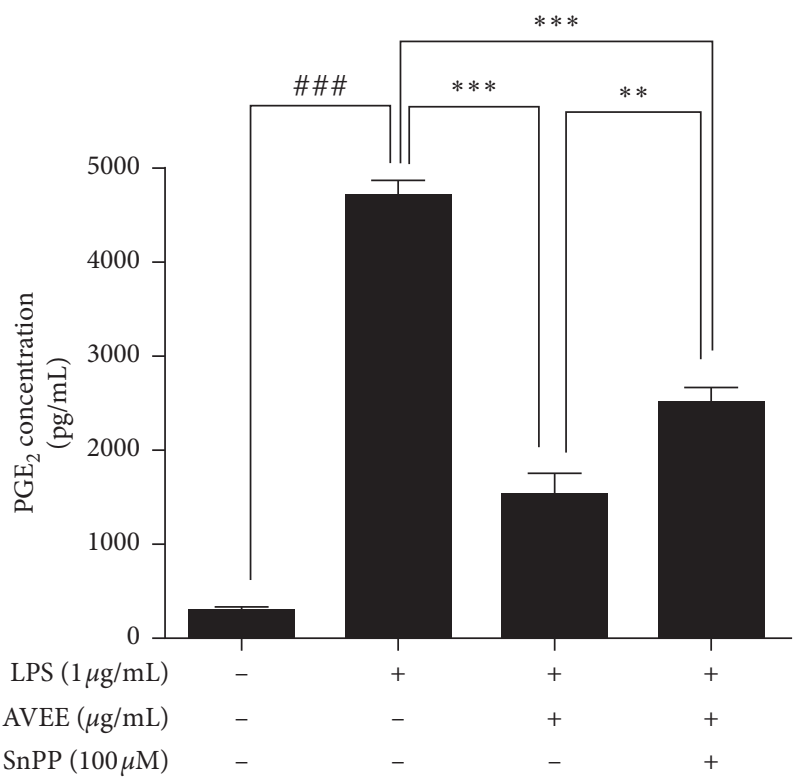

(b)

Figure 5: Continued. 


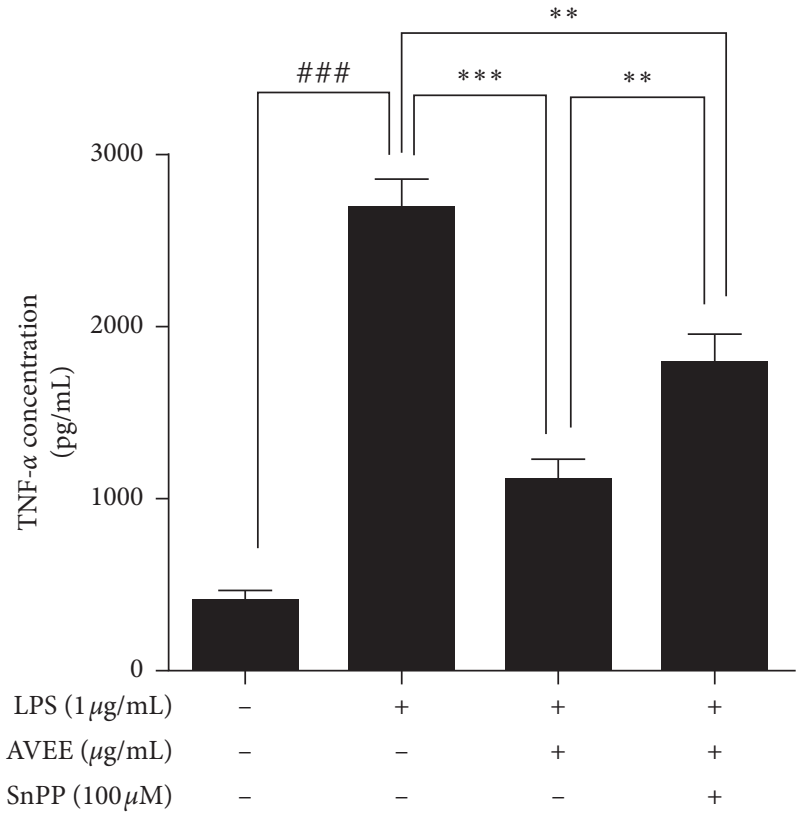

(c)

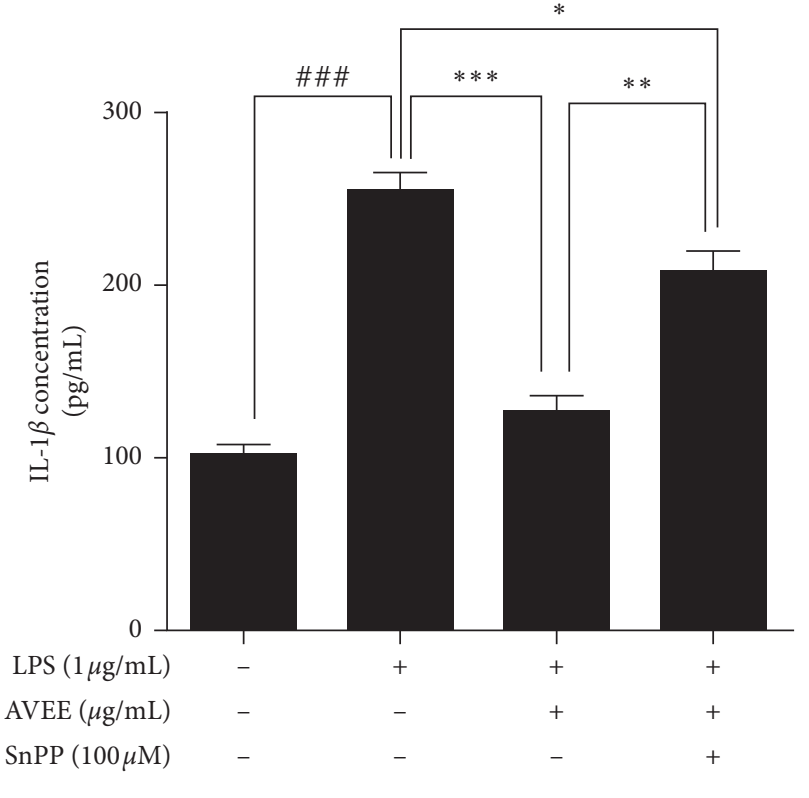

(d)

FIGURE 5: Effects of AVEE on SnPP-induced proinflammatory enzyme and cytokine levels. RAW 264.7 cells were incubated with SnPP (an HO- 1 inhibitor) for $1 \mathrm{~h}$ treated with AVEE at $100 \mu \mathrm{g} / \mathrm{mL}$ for $3 \mathrm{~h}$ and stimulated with LPS $(1 \mu \mathrm{g} / \mathrm{mL})$. NO (a), PGE 2 (b), TNF- $\alpha$ (c), and IL- $1 \beta$ (d) levels were assessed by ELISA as described in Materials and Methods. Results are presented as the means \pm SDs of three independent experiments. ${ }^{\# \#} P<0.005$ versus treatment naïve controls. ${ }^{* *} P<0.01$ and ${ }^{* * *} P<0.005$ versus the indicated group.

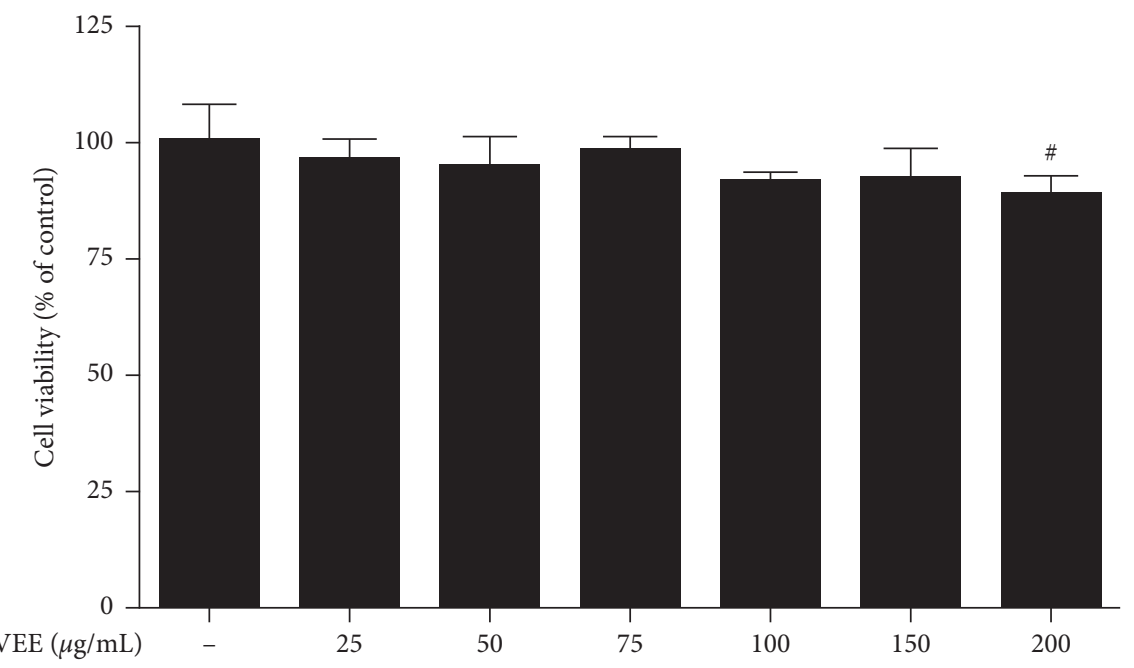

(a)

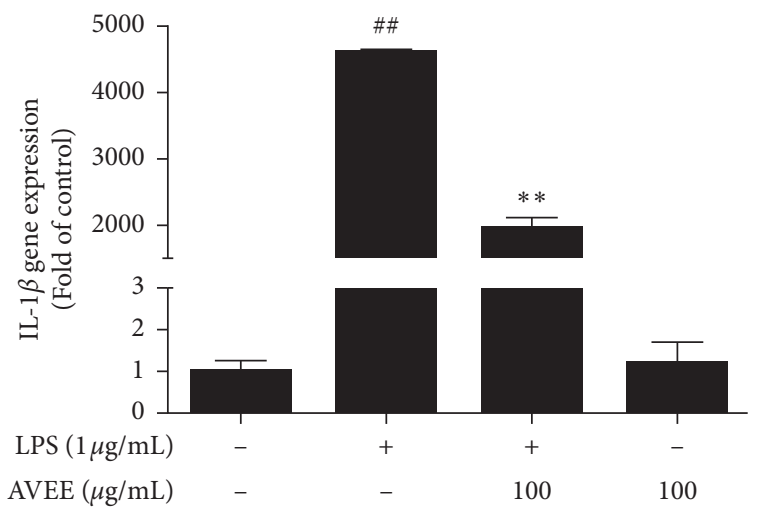

(b)

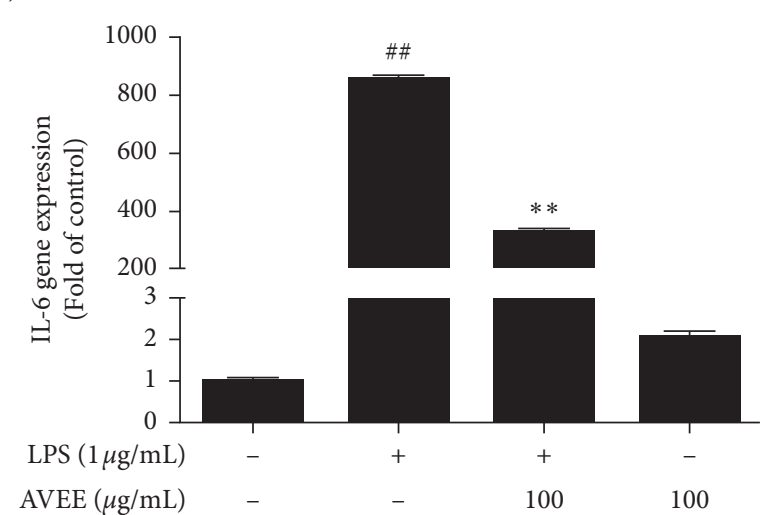

(c)

Figure 6: Continued. 


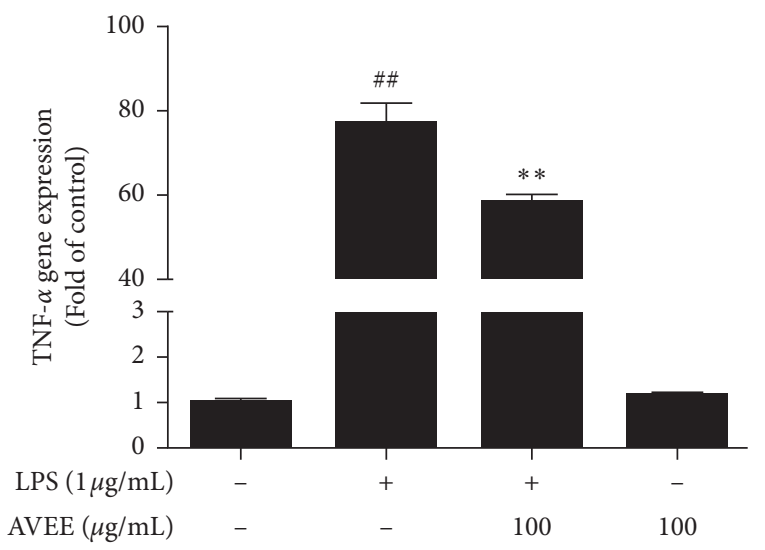

(d)

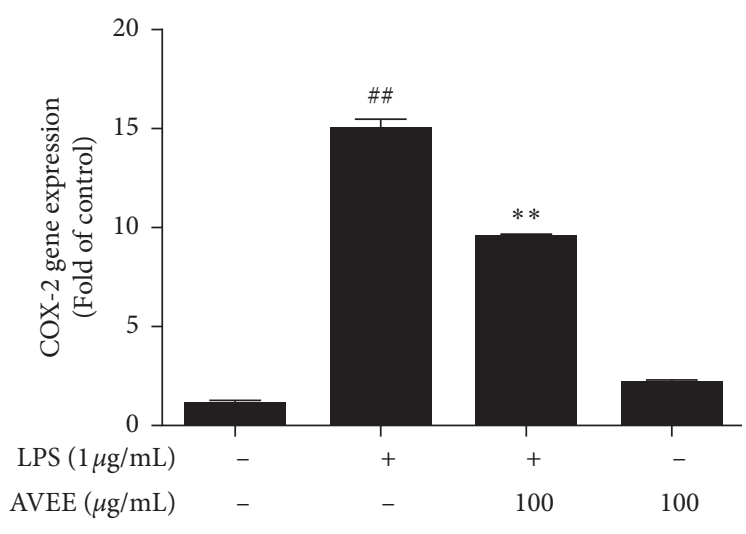

(e)

FIGURE 6: Effects of AVEE on proinflammatory gene expression in murine peritoneal macrophages. Murine macrophages were incubated with various concentrations of $\operatorname{AVEE}(25,50,75,100,150$, and $200 \mu \mathrm{g} / \mathrm{mL})$ for $24 \mathrm{~h}$. Cell viabilities were measured using an MTT assay (a). Isolated peritoneal murine macrophages were incubated with AVEE $(100 \mu \mathrm{g} / \mathrm{mL})$ for $3 \mathrm{~h}$ and stimulated with LPS ( $1 \mu \mathrm{g} / \mathrm{mL})$. IL- $1 \beta$ (b), IL-6 (c), COX-2 (d), and TNF- $\alpha$ (e) mRNA expressions are presented as fold increases versus treatment naïve controls. Results are presented as the means \pm SDs of three independent experiments. ${ }^{\#} P<0.01$ versus treatment naïve controls. ${ }^{* *} P<0.01$ versus LPS treated controls.

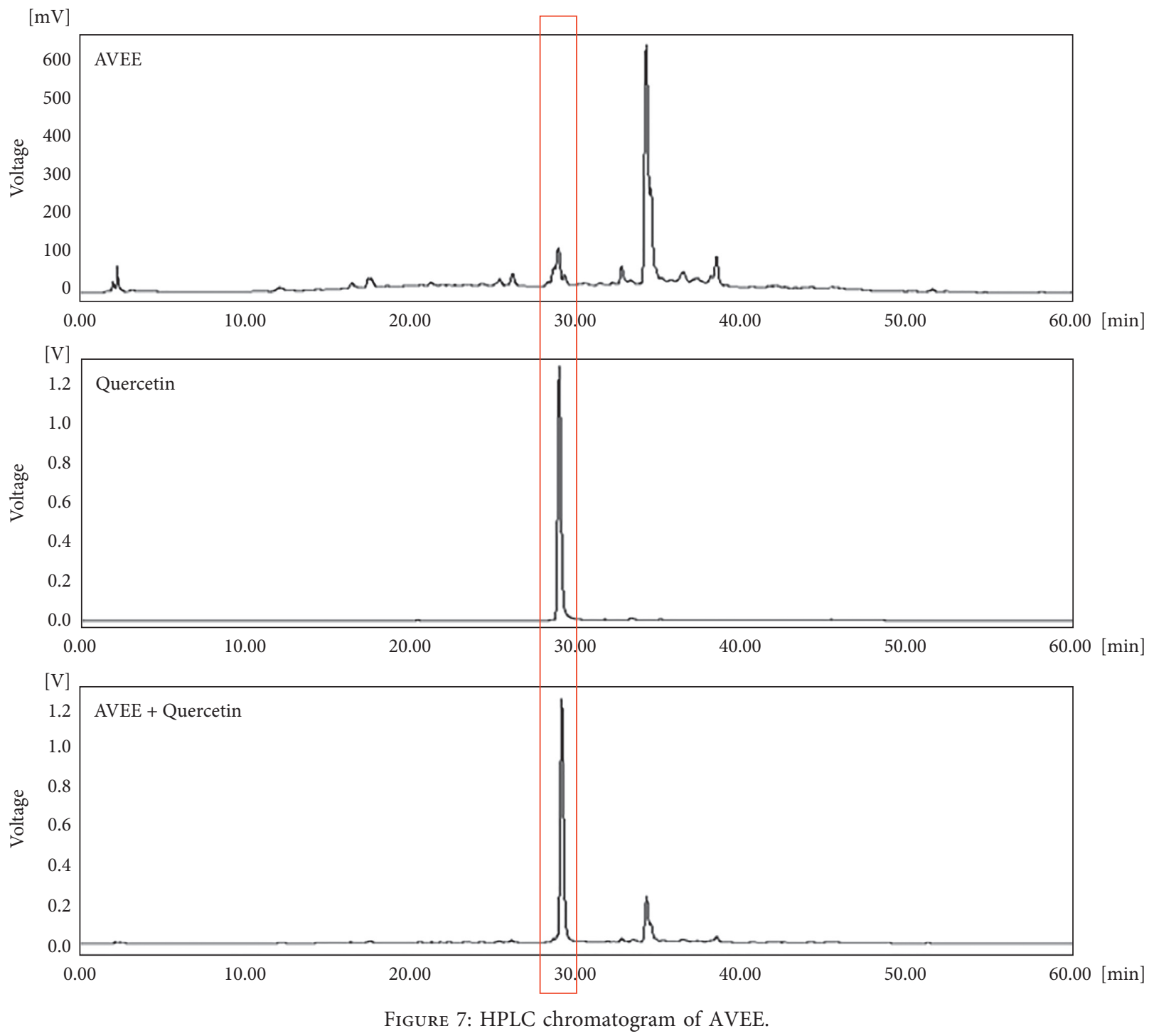


(IKK) complex [41]. In the present study, AVEE pretreatment blocked LPS-induced I $\kappa$ B phosphorylation and inhibited the translocation of NF- $\kappa \mathrm{B}$ in murine macrophages, as evidenced by immunoblot and immunofluorescence images, which indicated AVEE suppressed LPS-induced inflammatory responses by blocking the NF- $\kappa \mathrm{B}$ pathway.

LPS-stimulated macrophages create excessive oxidative stress and produce nitric oxide, which can activate upstream kinases of NF- $\kappa \mathrm{B}$ such as IKK and Akt $[42,43]$. The importance of HO-1 expression in the maintenance of redox balance was demonstrated in a study on HO-1 knockout mice, which exhibited high levels of ROS, proinflammatory cytokines, and oxidized LDL in macrophages [44] and, thus, demonstrated that HO-1 importantly protects macrophages from ROS [45] by inhibiting NF- $\kappa \mathrm{B}$ signaling and inflammatory responses. Furthermore, HO-1 expression is preferentially expressed in M2 macrophages and causes a shift from an inflammatory to an anti-inflammatory state and, thus, facilitates the resolution of inflammatory processes [46].

In the following experiment, AVEE notably induced HO- 1 expression in presence of $10 \mu \mathrm{M}$ CoPP and induced the nuclear localization of Nrf2, which is responsible for upregulation of cellular antioxidant defense mechanisms. Clearer evidences came from the assay with SnPP, which is inhibitor of HO-1, when SnPP treatment markedly depressed effect of AVEE against LPS. For example, suppressions of LPS-induced increases in inflammatory markers by AVEE (e.g., NO, PGE2, TNF- $\alpha$, and IL- $1 \beta$ ) were inhibited by SnPP. These observations suggest that AVEE reinforces the Nrf2/HO-1 pathway and promotes antioxidant status in macrophages challenged by LPS. Furthermore, the abovementioned results were wholly supported by the results obtained in our ex vivo study conducted using macrophages harvested from mice peritoneal cavity.

In a pioneering study, sulforaphane was found to suppress LPS-induced inflammation via the Nrf2 pathway in mouse peritoneal macrophages [47], and a large number of natural compounds have been reported to activate Nrf2 [48]. Though we elucidated the effects of AVEE on the Nrf2/HO-1 pathway, we did not identify the compound responsible in AVEE. Nevertheless, HPLC showed AVEE contained quercetin, which has been suggested to be an activator of the Nrf2/HO-1 pathway [49]. However, A. villosum has also been reported to contain several potential Nrf2 activators (e.g., bornyl acetate, camphor, borneol, $\beta$-sitosterol, and vanillic acid) [31]. Thus, we suggest further study be undertaken to identify the compound primarily responsible for the effects of AVEE observed in the present study.

\section{Conclusion}

Our findings show AVEE suppresses the NF- $\kappa$ B signaling pathway and subsequent inflammatory responses by activating the Nrf2/HO-1 pathway and, thus, reduces oxidative stress in murine macrophages. We tentatively suggest that quercetin in AVEE is responsible for these beneficial effects. Further study is required to assess effects of AVEE on ROSrelated chronic inflammatory diseases in vivo.

\section{Data Availability}

All data used to support the findings of this study are included within the article.

\section{Conflicts of Interest}

The authors have no conflicts of interest to declare.

\section{Authors' Contributions}

Dong-Woo Lim carried out experiments and revised the manuscript. Hee-Jin Choi carried out experiments and wrote the manuscript. Sun-Dong Park designed the study and analyzed data. Hyuck Kim processed the data and revised the manuscript. Ga-Ram Yu carried out experiments and processed the supplementary data for revision. Jai-Eun Kim designed the study and interpreted the results. WonHwan Park supervised and directed the study. All authors reviewed the results and approved the final version of the manuscript.

\section{Acknowledgments}

This research was supported by the Basic Science Research Program through the National Research Foundation of Korea (NRF) funded by the Korean Ministry of Education (NRF-2016R1D1A1B03933213).

\section{References}

[1] E. Birben, U. M. Sahiner, C. Sackesen, S. Erzurum, and O. Kalayci, "Oxidative stress and antioxidant defense," World Allergy Organization Journal, vol. 5, no. 1, pp. 9-19, 2012.

[2] K. Brieger, S. Schiavone, F. J. Miller, and K. H. Krause, "Reactive oxygen species: from health to disease," Swiss Medical Weekly, vol. 142, p. w13659, 2012.

[3] L. A. Sena and N. S. Chandel, "Physiological roles of mitochondrial reactive oxygen species," Molecular Cell, vol. 48, no. 2, pp. 158-167, 2012.

[4] M. Mittal, M. R. Siddiqui, K. Tran, S. P. Reddy, and A. B. Malik, "Reactive oxygen species in inflammation and tissue injury," Antioxidants \& Redox Signaling, vol. 20, no. 7, pp. 1126-1167, 2014.

[5] B. Uttara, A. Singh, P. Zamboni, and R. Mahajan, "Oxidative stress and neurodegenerative diseases: a review of upstream and downstream antioxidant therapeutic options," Current Neuropharmacology, vol. 7, no. 1, pp. 65-74, 2009.

[6] S. J. Forrester, D. S. Kikuchi, M. S. Hernandes, Q. Xu, and K. K. Griendling, "Reactive oxygen species in metabolic and inflammatory signaling," Circulation Research, vol. 122, no. 6, pp. 877-902, 2018.

[7] L. Ferrero-Miliani, O. H. Nielsen, P. S. Andersen, and S. E. Girardin, "Chronic inflammation: importance of NOD2 and NALP3 in interleukin-1beta generation," Clinical and Experimental Immunology, vol. 147, no. 2, pp. 227-235, 2007.

[8] T. Liu, L. Wu, D. Wang et al., "Role of reactive oxygen speciesmediated MAPK and NF- $\kappa \mathrm{B}$ activation inpolygonatum cyrtonemalectin-induced apoptosis and autophagy in human lung adenocarcinoma A549 cells," Journal of Biochemistry, vol. 160, no. 6, pp. 315-324, 2016. 
[9] C. M. Liu, Y. Z. Sun, J. M. Sun, J. Q. Ma, and C. Cheng, "Protective role of quercetin against lead-induced inflammatory response in rat kidney through the ROS-mediated MAPKs and NF-kappaB pathway," Biochimica et Biophysica Acta (BBA), vol. 1820, no. 10, pp. 1693-1703, 2012.

[10] C. Li, D. Ma, M. Chen et al., "Ulinastatin attenuates LPSinduced human endothelial cells oxidative damage through suppressing JNK/c-Jun signaling pathway," Biochemical and Biophysical Research Communications, vol. 474, no. 3, pp. 572-578, 2016.

[11] J.-Q. Ma, J. Ding, L. Zhang, and C.-M. Liu, "Ursolic acid protects mouse liver against $\mathrm{CCl} 4$-induced oxidative stress and inflammation by the MAPK/NF- $\kappa$ B pathway," Environmental Toxicology and Pharmacology, vol. 37, no. 3, pp. 975-983, 2014.

[12] H. Y. Tan, N. Wang, S. Li, M. Hong, X. Wang, and Y. Feng, "The reactive oxygen species in macrophage polarization: reflecting its dual role in progression and treatment of human diseases," Oxidative Medicine Cell Longevity, vol. 2016, Article ID 2795090, 16 pages, 2016.

[13] N. Fujiwara and K. Kobayashi, "Macrophages in inflammation," Current Drug Target -Inflammation \& Allergy, vol. 4, no. 3, pp. 281-286, 2005.

[14] H. J. Forman and M. Torres, "Reactive oxygen species and cell signaling: respiratory burst in macrophage signaling," American Journal of Respiratory Critical Care Medicine, vol. 166, no. S1, pp. S4-S8, 2002.

[15] Y. Zhang, S. Choksi, K. Chen, Y. Pobezinskaya, I. Linnoila, and Z.-G. Liu, "ROS play a critical role in the differentiation of alternatively activated macrophages and the occurrence of tumor-associated macrophages," Cell Research, vol. 23, no. 7, pp. 898-914, 2013.

[16] N. Dey, M. Sinha, S. Gupta et al., "Caspase-1/ASC inflammasome-mediated activation of IL- $1 \beta$-ROS-NF- $\kappa$ B pathway for control of trypanosoma cruzi replication and survival is dispensable in NLRP3-/- macrophages," PLoS One, vol. 9, no. 11, Article ID e111539, 2014.

[17] S. K. Biswas, "Does the interdependence between oxidative stress and inflammation explain the antioxidant paradox?" Oxidative Medicine Cell Longevity, vol. 2016, Article ID 5698931, 9 pages, 2016.

[18] F. Yan, Y. Chen, R. Azat, and X. Zheng, "Mulberry anthocyanin extract ameliorates oxidative damage in HepG2 cells and prolongs the lifespan of Caenorhabditis elegans through MAPK and Nrf2 pathways," Oxidative Medicine Cellular Longevity, vol. 2017, Article ID 7956158, 12 pages, 2017.

[19] T. Nguyen, P. Nioi, and C. B. Pickett, "The Nrf2-antioxidant response element signaling pathway and its activation by oxidative stress," Journal of Biological Chemistry, vol. 284, no. 20, pp. 13291-13295, 2009.

[20] J. Kim and Y. S. Keum, "NRF2, a key regulator of antioxidants with two faces towards cancer," Oxidative Medicine and Cellular Longevity, vol. 2016, Article ID 2746457, 7 pages, 2016.

[21] J.-M. Lee and J. A. Johnson, “An important role of Nrf2-ARE pathway in the cellular defense mechanism," BMB Reports, vol. 37, no. 2, pp. 139-143, 2004.

[22] Y. Naito, T. Takagi, and Y. Higashimura, "Heme oxygenase-1 and anti-inflammatory M2 macrophages," Archives of Biochemistry and Biophysics, vol. 564, pp. 83-88, 2014.

[23] K. Kawamura, K. Ishikawa, Y. Wada et al., "Bilirubin from heme oxygenase-1 attenuates vascular endothelial activation and dysfunction," Arteriosclerosis, Thrombosis, and Vascular Biology, vol. 25, no. 1, pp. 155-160, 2005.
[24] L. E. Otterbein, M. P. Soares, K. Yamashita, and F. H. Bach, "Heme oxygenase-1: unleashing the protective properties of heme," Trends in Immunology, vol. 24, no. 8, pp. 449-455, 2003.

[25] S. Immenschuh and G. Ramadori, "Gene regulation of heme oxygenase- 1 as a therapeutic target," Biochemical Pharmacology, vol. 60, no. 8, pp. 1121-1128, 2000.

[26] M. H. Kapturczak, C. Wasserfall, T. Brusko et al., "Heme oxygenase-1 modulates early inflammatory responses," The American Journal of Pathology, vol. 165, no. 3, pp. 1045-1053, 2004.

[27] H. Kumar, I.-S. Kim, S. V. More, B.-W. Kim, and D.-K. Choi, "Natural product-derived pharmacological modulators of Nrf2/ARE pathway for chronic diseases," Natural Product Reports, vol. 31, no. 1, pp. 109-139, 2014.

[28] S. Lu, T. Zhang, W. Gu et al., "Volatile oil of Amomum villosum inhibits nonalcoholic fatty liver disease via the gutliver Axis," Biomed Research International, vol. 2018, Article ID 3589874, 16 pages, 2018.

[29] Z. Chen, W. Ni, C. Yang et al., "Therapeutic effect of Amomum villosum on inflammatory bowel disease in rats," Frontiers in Pharmacology, vol. 9, p. 639, 2018.

[30] X. Wu, X. Li, F. Xiao, Z. Zhang, Z. Xu, and H. Wang, "Studies on the analgesic and anti-inflammatory effect of bornyl acetate in volatile oil from Amomum villosum," Zhong Yao Cai, vol. 27, no. 6, pp. 438-439, 2004.

[31] Z. Sheng-tan, W. Zhao-yu, W. Tie-shan, L. Miao-xia, and L. Jing-ming, "Composition and antimicrobial activities of essential oil of fructus amomi," Natural Product Research \& Development, vol. 23, no. 3, 2011.

[32] C. Chen, C. Fu, W. C. Ye, and G. X. Zhou, "Study on phenolic constituents of Amomum villosum," Zhong Yao Cai, vol. 35, no. 4, pp. 571-573, 2012.

[33] D. W. Cain, E. G. O'Koren, M. J. Kan et al., "Identification of a tissue-specific, C/EBP $\beta$-Dependent pathway of differentiation for murine peritoneal macrophages," The Journal of Immunology, vol. 191, no. 9, pp. 4665-4675, 2013.

[34] C.-S. Kim, T. Kawada, B.-S. Kim et al., "Capsaicin exhibits anti-inflammatory property by inhibiting IkB-a degradation in LPS-stimulated peritoneal macrophages," Cellular Signalling, vol. 15, no. 3, pp. 299-306, 2003.

[35] H. Fang, R. A. Pengal, X. Cao et al., "Lipopolysaccharideinduced macrophage inflammatory response is regulated by SHIP," The Journal of Immunology, vol. 173, no. 1, pp. 360-366, 2004.

[36] J. N. Sharma, A. Al-Omran, and S. S. Parvathy, "Role of nitric oxide in inflammatory diseases," Inflammopharmacology, vol. 15, no. 6, pp. 252-259, 2007.

[37] J. MacMicking, Q.-w. Xie, and C. Nathan, "Nitric oxide and macrophage function," Annual Review of Immunology, vol. 15, no. 1, pp. 323-350, 1997.

[38] C. S. Williams, M. Mann, and R. N. DuBois, "The role of cyclooxygenases in inflammation, cancer, and development," Oncogene, vol. 18, no. 55, pp. 7908-7916, 1999.

[39] C. C. Chen, M. W. Lin, C. J. Liang, and S. H. Wang, "The antiinflammatory effects and mechanisms of eupafolin in lipopolysaccharide-induced inflammatory responses in RAW264.7 macrophages," PLoS One, vol. 11, no. 7, Article ID e0158662, 2016.

[40] T. Liu, L. Zhang, D. Joo, and S. C. Sun, "NF-kappaB signaling in inflammation," Signal Transduction and Targeted Therapy, vol. 2, 2017.

[41] P. Baeuerle and D. Baltimore, "I kappa B: a specific inhibitor of the NF-kappa B transcription factor," Science, vol. 242, no. 4878, pp. 540-546, 1988. 
[42] D. Bai, L. Ueno, and P. K. Vogt, "Akt-mediated regulation of $\mathrm{NF} \kappa \mathrm{B}$ and the essentialness of $\mathrm{NF} \kappa \mathrm{B}$ for the oncogenicity of PI3K and Akt," International Journal of Cancer, vol. 125, no. 12, pp. 2863-2870, 2009.

[43] S. H. Kim, V. J. Johnson, T.-Y. Shin, and R. P. Sharma, "Selenium attenuates lipopolysaccharide-induced oxidative stress responses through modulation of p38 MAPK and NF$\kappa \mathrm{B}$ signaling pathways," Experimental Biology and Medicine, vol. 229, no. 2, pp. 203-213, 2004.

[44] L. D. Orozco, M. H. Kapturczak, B. Barajas et al., "Heme oxygenase-1 expression in macrophages plays a beneficial role in atherosclerosis," Circulation Research, vol. 100, no. 12, pp. 1703-1711, 2007.

[45] X. Xu, H. Li, X. Hou et al., "Punicalagin induces Nrf2/HO-1 expression via upregulation of PI3K/AKT pathway and inhibits LPS-induced oxidative stress in RAW264.7 macrophages," Mediators Inflammations, vol. 2015, Article ID 380218, 11 pages, 2015.

[46] E. Sierra-Filardi, M. A. Vega, P. Sanchez-Mateos, A. L. Corbi, and A. Puig-Kroger, "Heme Oxygenase-1 expression in M-CSF-polarized M2 macrophages contributes to LPS-induced IL-10 release," Immunobiology, vol. 215, no. 9-10, pp. 788-795, 2010.

[47] W. Lin, R. T. Wu, T. Wu, T.-O. Khor, H. Wang, and A.-N. Kong, "Sulforaphane suppressed LPS-induced inflammation in mouse peritoneal macrophages through $\mathrm{Nrf2}$ dependent pathway," Biochemical Pharmacology, vol. 76, no. 8, pp. 967-973, 2008.

[48] K. C. Wu, P. R. McDonald, J. Liu, and C. D. Klaassen, "Screening of natural compounds as activators of the keap1nrf2 pathway," Planta Medica, vol. 80, no. 1, pp. 97-104, 2014.

[49] G. Y. Sun, Z. Chen, K. J. Jasmer et al., "Quercetin attenuates inflammatory responses in BV-2 microglial cells: role of MAPKs on the Nrf2 pathway and induction of heme oxygenase-1," PLoS One, vol. 10, no. 10, Article ID e0141509, 2015. 